\title{
Hepatobiliary and pancreatic surgery in the elderly: Current status
}

\author{
Davide Papis ${ }^{1}$, Alessio Vagliasindi ${ }^{2}$, and Pietro Maida ${ }^{1}$ \\ ${ }^{1}$ General Surgery Unit, Del Mare Hospital, Naples, \\ ${ }^{2}$ General Surgery Unit, Santa Maria delle Croci Hospital, Ravenna, Italy
}

\begin{abstract}
Hepato-pancreatico-biliary (HPB) surgery includes major hepatic resection and pancreatic surgery, both procedures are complex and have a potentially high complication rate. The presence of centers of excellence with a high patients volume has lowered the complication and increased the resection rate. Increased life expectancy and improved general health status have increased the number of elderly patients eligible for major surgery. Since old patients have more co-morbidities and decreased life expectancy, the benefit of these procedures need to be critically evaluated in this group. Analysis of the literature related to this argument demonstrated that pancreatoduodenectomy can be performed safely in selected elderly patients (70 years of age or older), with morbidity and mortality rates comparable those observed in younger patients. This aspect was also confirmed by cost analysis studies that reported similar data in both groups. Similar findings are also reported for major hepatic resection in elderly patients with either hepatocellular carcinoma (HCC), Klatskin tumor or gallbladder carcinoma. More studies are needed regarding the subgroup of very elderly patients (80 years or older). Nevertheless, those elderly patients who will benefit from surgery must be adequatelly selected. (Ann Hepatobiliary Pancreat Surg 2020;24:1-5)
\end{abstract}

Key Words: Liver; Pancreas; Surgery; Elderly

\section{INTRODUCTION}

At the beginning of the last century the word 'elderly' was synonymous with disease and the life expectancy of the population was calculated at around 50 years in the USA. Improvements in social and working conditions, nutrition and medical progress have significantly increased life expectancy which is now 76 years for men and 80 years for women in the USA. This has rapidly expanded the number of elderly patients increased life expectancy was accompanied by an increase in the number of elderly patients eligible for surgery. ${ }^{1}$ Malignant hepato-pancreato-biliary (HPB) tumors have their highest incidence in the sixth to eighth decades of life and more than $50 \%$ of patients with a malignancies are over 70 years of age at diagnosis. Surgical resection is the only potentially curative treatment option for most types of malignant HPB tumors, if the disease is resectable and limited. ${ }^{2}$ Although advanced age is still considered a contraindication to ma- jor surgery, nowadays, in specialized and high volume centers, surgery is often offered to old patients. Infact, if we consider that the life expectancy of a person respectively at age 70 is 13 years, at 80 is 8 years and at 85 is 6 years, it is of great importance to treat elderly people properly by attempting to offer them radical surgery in accordance with their co-morbidities and functional status. ${ }^{3}$ Another argument against complex surgery in the elderly may be related to the economic relevance of HPB surgery since liver and pancreatic resections are among the most expensive abdominal surgical procedures. Cost control is nowadays a very important aspect of many health systems, which raises the question what proportion of health care resources should be allocated to the older population. This is, probably, to become one of the most discussed aspects of health care delivery. ${ }^{4}$ The present review article analyzes the feasibility of hepatobiliarypancreatic surgery in the elderly with a particular interest on patients older than 80 years.

Received: August 13, 2019; Revised: September 14, 2019; Accepted: September 16, 2019

Corresponding author: Davide Papis

General Surgery Unit, Del Mare Hospital, Viale delle Metamorfosi, Naples 80147, Italy

Tel: +3908118775110, Fax: +390812544825, E-mail: davide.papis@gmail.com

Copyright (C) 2020 by The Korean Association of Hepato-Biliary-Pancreatic Surgery

This is an Open Access article distributed under the terms of the Creative Commons Attribution Non-Commercial License (http://creativecommons.org/ licenses/by-nc/4.0) which permits unrestricted non-commercial use, distribution, and reproduction in any medium, provided the original work is properly cited. Annals of Hepato-Biliary-Pancreatic Surgery - pISSN: 2508-5778 - elSSN: 2508-5859 


\section{PREOPERATIVE ASSESMENT}

The main potential limitation of major HPB surgery in very elderly patients is the anticipated higher risk when compared to younger; for this reason better understand of surgical risk is crucial in optimising treatment in this patient group. In response to this, geriatricians have developed a comprehensive geriatric assesment tool (CGA), based on a short interview with the patient, which has been put together with used surgical risk assesment tools in order to obtain a comprehensive picture, in terms of health and functionality of oncogeriatric patients. This battery of validated instruments forms the "Preoperative Assesment of Cancer in the Elderly" (PACE) which comprends: mini-mental state inventory (MMI), activities of daily living (ADL), instrumental activities of daily livings (IADL), geriatric depression scale (GDS), brief fatigue inventory (BFI), performance status (PS), american society for anaesthesiologia (ASA) and Satoriano's index of comorbidities (SIC). ${ }^{5}$ Instead the current American college of Cardiology and American Heart Association (ACC/ AHA) have developed guidelines to drive the decision process in case of surgery in elderly patients and are resumed in eight key questions: 1. Urgency for surgery; 2. Revascularization; 3. Recent evaluation; 4. Disease instability; 5. Intermediate risk; 6. Functional capacity; 7. Minor or no clinical predictor; 8. Non-invasive testing. Post-operative pneumonia in older patients is associated with a $15-20 \%$ mortality rate and must be treated with aggressive therapy. Regarding emergency surgeries, they are associated with a higher overall death rate in all age groups, this finding is most apparent in older patients who have the highest rates as a consequence of a greater number of complications. In addition, the identical surgical disease in the elderly patients may present later in its course, and diagnosis can be delayed because of atypical presentation. A previous neuro- logical event, such as stroke, may increase the risk of aspiration by making it difficult to swallow, to move food through the oesophagus, and to control respiratory secretion. Finally, taking the time to discuss the surgery with the older patients and their families promotes a clear understanding of risk and benefits and will help to reduce the chance of false expectations with surgery. ${ }^{6}$

\section{LIVER SURGERY}

Liver resection is the treatment of choice for a range of primary and secondary hepatic diseases. ${ }^{7}$ As for pancreatic surgery, adavnces in anaesthesiology, surgery and pre-op assesment have increased the number of patients evaluated for liver resections and the rise in life expectancy has led to an increase in the number of elderly patient candidates for curative liver major and minor resection. Potential age-associated reduction in liver volume, hepatic blood flow, and regenerative capacity might be responsible, associated to a growing level of steatosis, for higher risks associated with liver resection in elderly patients. $^{8}$

Primary tumors of the liver are among the most common solid tumors worldwide and the incidence of HCC is the fourth highest among all tumors. ${ }^{9} \mathrm{HCC}$ frequently arises in the setting of cirrhosis, appearing 20-30 years following the initial insult to the liver. However, 25\% of patients have no history of risk factors for the development of cirrhosis. The extent of hepatic dysfunction limits treatment options, and as many patients die from liver failure as from tumour progression. The peak incidence of HCC around the sixth decade of life, combined with the ageing of the world population, results in a dramatically increasing elderly population of HCC patients considered for hepatic surgery.

Liver transplantation is theoretically the optimal treatment for HCC because it is the only method of treating both the tumor and the underlying cirrhosis. In patients with HCC and chirrosis, transplantation based on the Milan criteria achives a better outcome than hepatic resection. When liver transplantation is problematic or not possible, liver resection remains the preferred treatment with 5 -years survival rates ranging from $40 \%$ to $50 \%$. In patients not fit for surgery or with an unresectable tumor, other modalities of treatment, like transcatheter arterial chemoembolization (TACE) and radiofrequency abalation (RFA), are available according to BCLC criteria.,

Recent studies have shown the safety and feasibility of hepatectomy for HCC patients older than 70 years of age with similar blood loss, during surgery, and long-term outcome, after surgery, compared to younger patients. Although the older patients had more co- morbidities, this had no impact on post-operative complication rates, which 
in most studies were similar in both groups. Mortality rates also range from $3 \%$ to $40 \%$ in most of the studies published while morbidity range from $14 \%$ to $41 \%$. Moreover, in recent decades the mortality rate was below $10 \%$ and did not significantly differ between elderly and younger patients. ${ }^{9-11}$ Just as in the general population, cirrhosis and Child-Pugh $\mathrm{B} / \mathrm{C}$ are predictors of poor survival in elderly patients. ${ }^{12}$

Unluckly there are no many informations about postoperative outcome after liver surgery for HCC in the very elderly subgroup (age $>80$ ). In a retrospective study of $1999 \mathrm{Wu}$ et al. ${ }^{13}$ reported no significant differences between octagenarians and youngers regarding operative morbidity and mortality.

Similar results have been found even in studies which have evaluated short and long term outcome after surgery in elderly and younger patients undergone liver resection for colorectal liver metastases (CLM). ${ }^{14}$ Mortality and morbidity were $2 \%$ and $14 \%$ in the younger while those were $3.8 \%$ and $16 \%$ in elderly patients. ${ }^{15}$ In a prospective study Adam et al found no significant differences in the 3 -years survival rate between the two groups $(57.1 \%$ in age $>70$ group, $60.1 \%$ in age $<70$ group respectively). ${ }^{1}$

Analogue results have been found in the very elderly patient subgroup ( $>80$ years). ${ }^{1,7}$ In all the studies age was not independently associated with postoperative mortality.

Furthermore, for gallbladder cancer and hilar bile duct cancer (Klatskin tumour) superimposable data were reported in younger and elderly patients although few studies were available. ${ }^{16}$

These data suggest that selected elderly patients also benefit from hepatic resection for HCC and CLM in the same way as do younger patients. ${ }^{17}$

\section{PANCREATIC SURGERY}

Pancreatic cancer is an aggressive malignancy with extremely poor prognosis and ranks as the fourth- or fifth-leading cause of cancer death in Western countries. At time of diagnosis, most patients have locally advanced disease and/or distant metastatic lesions precluding radical resection; the five-year survival rate is around $10-25 \%$, even after R0 cancer resection and it is higher for patients with distal bile duct cancer (20-25\%), ampullary cancer $(30-40 \%)$ and duodenal cancer $(50-60 \%) .{ }^{18}$ Median age at time of diagnosis is 72 years, and with the growing of the elderly population in recent decades, patients aged more than 70 years with resectable pancreatic cancer will be seen more and more often. As pancreatic resection became safer and was accepted as the standard of care, the indications remained narrow and was not commonly performed in patients over 70 and rarely in patients over 80 but the establishment of centres with a high volume of pancreatic cancer patients has generated a reduction in the rate of operative complications, prompting surgeons to aggressively approach pancreatic cancer in elderly patients as well. ${ }^{19}$ Anyway pancreaticoduodenectomy (PD) remains the only curative treatment currently available for malignant or potentially malignant tumors of the biliarypancreatic junction and, despite surgical skills and technologies improvent, it is still associated with a mortality rate of $2-4 \%$ and a morbidity rate of more than $30 \%{ }^{20}$ It is important to remember that people undergoing surgery, whatever their age, should be selected for good underlying health.

Different studies from high volume centers have been performed to analyse the postoperative outcome after PD, comparing elderly patients to younger. Most studies compared perioperative and long-term outcome in patients younger than 70 years versus those older than 70 years of age. Operative data demonstrated that intra-operative blood loss and operative times were similar for younger and older patients, suggesting that the extent of surgical aggressiveness is independent of age. In a retrospective study of 142 patients, Suzuki et al. have not reported difference in mortality $(0 \%)$, morbidity $(24.3 \%$ in patients $<75$ years, $29.5 \%$ in patients $>75$ years) and blood lost. $^{21}$ Similar findings have been reported by di Sebastiano et al. ${ }^{17}$ in a series of 33 patients. Most studies compared perioperative and long-term outcome in patients younger than 70 years versus those older than 70 years of age. Operative data demonstrated that intra-operative blood loss and operative times were similar for younger and older patients, suggesting that the extent of surgical aggressiveness is independent of age. ${ }^{21}$ In another retrospective study performed using data from the Surveillance, Epidemiology and end Results, USA, Riall et al. analysed 9553 patients divided in 3 groups $(<70$, $71-79$ and $>80)$. They found that surgical resection rate decreased from $39 \%$ in patients younger than 70 to $5 \%$ 
in partecipants aged 85 and older while mortality increased with increasing age: 30-day mortality increased from $7 \%$ in younger than 70 to $11.5 \%$ in older than 85 but it was not statistically significant; another interesting finding was that the benefit of surgical resection did not significantly change with age. ${ }^{22}$

On the other side Sulpice et al. $^{20}$ in a retrospective study of 314 patients found that mortality and morbidity increased in the group of patients older than 75 years: mortality was $24 \%$ in the older versus $3.6 \%$ in the youngers and morbidity was $14.6 \%$ and $4.4 \%$ respectively. Such findings have been confirmed by a meta-analysis of 11 studies comprising 5186 patients performed by Sukharamwala. ${ }^{19}$ Meanwhile, the majority of the other studies reported complication rates and hospital stays to be comparable between the younger and older populations, especially if we consider that patients classed as ASA IV (American Society of Anaes- thesiologists, high-risk patients) were excluded from pancreatic surgery. ${ }^{23}$

Another study performed by the Southampton HPB unit, compared patients older than 75 years to youngers both undergone to pancratoduodenectomy. Data were analysed from a prospectively collected database and outcomes compared. Five hundred and twenty-four patients were included (Group A n=422, Group B n=102). Postoperative cardiac events and peri-operative mortality were higher in the elderly ( 10.8 vs $3.6 \%, p=0.008$ and 5.9 vs $1.9 \%, 0.037$, respectively). Multivariate analysis revealed only ASA score (OR 0.279 , 95\% CI $0.063-1.130$ ), postpancreatectomy haemorrhage (OR $0.055,95 \%$ CI $0.006-$ 0.518 ) and pulmonary embolism (OR 0.03 , 95\% CI 0.00 0.148 ) as independent risk factors for peri-operative mortality. Age was not (OR 0.978, 95\% CI 0.911-1.049). Median survival was 22 months in Group A and 19 months in Group B $(p=0.165)$. Predictors of five-year survival included vascular resection (OR $0.171,95 \%$ CI 0.053-0.549), positive margin (OR 0.256, 95\% CI 0.1020.641), lympho-vascular invasion (OR 0.392 , 95\% CI 0.160-0.958) and lymph node ratio (OR 67.381, 95\% CI 3.301-1375.586), but not age (OR 1.012, 95\% CI 0.972$1.054) .^{24}$

The impact of pancreatic surgery in patients older than 80 years was also evaluated by Melis et al. ${ }^{25}$ in a series of 200 patients. As compared to concurrent patients younger than 80 years, the two groups were statistically similar with respect to sex, race, intra-operative blood loss, and type of pancreatico-duodenectomy performed. Octagenarians had a longer post-operative stay (20 vs 14 days) and higher overall morbidity (68\% vs $44 \%)$; there was a death in each group and 1 -year survival was the same. Another larger retrospective study by Makary et al. $^{26}$ on 2688 patients showed that age did not result in increased perioperative mortality in patients $>80$ years of age or an increase in complications; however, age approached statistical significance with both of these outcome variables. A recent study showed how in the last years the use of multimodality therapy (surgery+chemotherapy) in older patients with pancreatic adenocarcinoma has increased as well. ${ }^{27}$

These data demonstrate that pancreatico-duode- nectomy can be safely performed in selected patients 80 years of age or older, with morbidity and mortality rates approaching those observed in younger patients.

\section{CONCLUSIONS}

Nowadays, with the improvement of surgical skills and new technologies available, HPB major surgery can be considered safe and feasible even in carefully selected elderly patients. ${ }^{28}$ Usually elderly patients may have more comorbidities and a long hospital-stay can increase complications rate and costs: in light of this a crucial role is assigned to patients' preoperative assessment. ${ }^{5}$ If the patient has few co-morbidities and a good general health status, then malignant HPB tumors can be resected in elderly patients, especially older than 70 years, without generating higher costs and with a rate of complications that is acceptable as compared to that of younger patients. This review shows how further randomized studies are needed for a better evaluation of short-term and long-term outcome after HPB surgery in the subgroup of very elderly patients (older than 80 years) compared with the youngers, considering quality of life as primary endpoint too. ${ }^{4}$

\section{ORCID}

Davide Papis: https://orcid.org/0000-0002-8983-2158

Alessio Vagliasindi: https://orcid.org/0000-0001-8414-8309

Pietro Maida: https://orcid.org/0000-0002-5456-2733 


\section{AUTHOR CONTRIBUTION}

Papis and Vagliasindi performed research and wrote the text; Maida checked english and made the revision.

\section{REFERENCES}

1. Adam R, Frilling A, Elias D, Laurent C, Ramos E, Capussotti L, et al.; LiverMetSurvey Centres. Liver resection of colorectal metastases in elderly patients. Br J Surg 2010;97:366-376.

2. Demols A, Maréchal R, Devière J, Van Laethem JL. The multidisciplinary management of gastrointestinal cancer. Biliary tract cancers: from pathogenesis to endoscopic treatment. Best Pract Res Clin Gastroenterol 2007;21:1015-1029.

3. DiCarlo V, Balzano G, Zerbi A, Villa E. Pancreatic cancer resection in elderly patients. Br J Surg 1998;85:607-610.

4. Connor S, Sakowska M. Age and pancreaticoduodenctomy: is it really about mortality? HPB (Oxford) 2012;14:647-648.

5. PACE participants, Audisio RA, Pope D, Ramesh HS, Gennari $\mathrm{R}$, van Leeuwen BL, et al. Shall we operate? Preoperative assessment in elderly cancer patients (PACE) can help. A SIOG surgical task force prospective study. Crit Rev Oncol Hematol 2008;65:156-163.

6. Bonow RO, Masoudi FA, Rumsfeld JS, Delong E, Estes NA 3rd, Goff DC Jr, et al.; American College of Cardiology; American Heart Association Task Force on Performance Measures. ACC/AHA classification of care metrics: performance measures and quality metrics: a report of the American College of Cardiology/American Heart Association Task Force on Performance Measures. J Am Coll Cardiol 2008;52:2113-2117.

7. Riffat $\mathrm{F}$, Chu F, Morris DL. Liver resection in octogenarians. HPB (Oxford) 2006;8:206-210.

8. Sarno G, Poston GJ. Liver surgery in elderly patients. In: Poston GJ, D'Angelica M, Adam R, eds. Surgical management of hepatobiliary and pancreatic disorders. 2nd ed. London: Informa Healthcare, 2010: pp. 46-52.

9. Huang J, Li BK, Chen GH, Li JQ, Zhang YQ, Li GH, et al. Long-term outcomes and prognostic factors of elderly patients with hepatocellular carcinoma undergoing hepatectomy. J Gastrointest Surg 2009;13:1627-1635.

10. Menon KV, Al-Mukhtar A, Aldouri A, Prasad RK, Lodge PA, Toogood GJ. Outcomes after major hepatectomy in elderly patients. J Am Coll Surg 2006;203:677-683.

11. Kondo K, Chijiiwa K, Funagayama M, Kai M, Otani K, Ohuchida J. Hepatic resection is justified for elderly patients with hepatocellular carcinoma. World J Surg 2008;32:2223-2229.

12. Ijtsma AJ, Boevé LM, van der Hilst CS, de Boer MT, de Jong KP, Peeters PM, et al. The survival paradox of elderly patients after major liver resections. J Gastrointest Surg 2008;12:21962203.

13. Wu CC, Chen JT, Ho WL, Yeh DC, Tang JS, Liu TJ, et al.
Liver resection for hepatocellular carcinoma in octogenarians. Surgery 1999;125:332-338.

14. de Liguori Carino $\mathrm{N}$, van Leeuwen $\mathrm{BL}$, Ghaneh $\mathrm{P}, \mathrm{Wu} \mathrm{A}$, Audisio RA, Poston GJ. Liver resection for colorectal liver metastases in older patients. Crit Rev Oncol Hematol 2008;67:273278.

15. Cho SW, Steel J, Tsung A, Marsh JW, Geller DA, Gamblin TC. Safety of liver resection in the elderly: how important is age? Ann Surg Oncol 2011;18:1088-1095.

16. Onoyama H, Ajiki T, Takada M, Urakawa T, Saitoh Y. Does radical resection improve the survival in patients with carcinoma of the gallbladder who are 75 years old and older? World J Surg 2002;26:1315-1318.

17. di Sebastiano P, Festa L, Büchler MW, di Mola FF. Surgical aspects in management of hepato-pancreatico-biliary tumours in the elderly. Best Pract Res Clin Gastroenterol 2009;23:919-923.

18. Riall TS. What is the effect of age on pancreatic resection? Adv Surg 2009;43:233-249.

19. Sukharamwala P, Thoens J, Szuchmacher M, Smith J, DeVito P. Advanced age is a risk factor for post-operative complications and mortality after a pancreaticoduodenectomy: a meta-analysis and systematic review. HPB (Oxford) 2012;14:649-657.

20. Sulpice L, Rayar M, D'Halluin PN, Harnoy Y, Merdrignac A, Bretagne JF, et al. Impact of age over 75 years on outcomes after pancreaticoduodenectomy. J Surg Res 2012;178:181-187.

21. Suzuki S, Kaji S, Koike N, Harada N, Suzuki M. Pancreaticoduodenectomy can be safely performed in the elderly. Surg Today 2013;43:620-624.

22. Riall TS, Sheffield KM, Kuo YF, Townsend CM Jr, Goodwin JS. Resection benefits older adults with locoregional pancreatic cancer despite greater short-term morbidity and mortality. J Am Geriatr Soc 2011;59:647-654.

23. Bathe OF, Levi D, Caldera H, Franceschi D, Raez L, Patel A, et al. Radical resection of periampullary tumors in the elderly: evaluation of long-term results. World J Surg 2000;24:353-358.

24. Shamali A, De'Ath HD, Jaber B, Abuawad M, Barbaro S, Hamaday Z, et al. Elderly patients have similar short term outcomes and five-year survival compared to younger patients after pancreaticoduodenectomy. Int J Surg 2017;45:138-143.

25. Melis M, Marcon F, Masi A, Pinna A, Sarpel U, Miller G, et al. The safety of a pancreaticoduodenectomy in patients older than 80 years: risk vs. benefits. HPB (Oxford) 2012;14:583-588.

26. Makary MA, Winter JM, Cameron JL, Campbell KA, Chang D, Cunningham SC, et al. Pancreaticoduodenectomy in the very elderly. J Gastrointest Surg 2006;10:347-356.

27. Parmar AD, Vargas GM, Tamirisa NP, Sheffield KM, Riall TS. Trajectory of care and use of multimodality therapy in older patients with pancreatic adenocarcinoma. Surgery 2014;156:280289.

28. Lu Q, Lu JW, Wu Z, Liu XM, Li JH, Dong J, et al. Perioperative outcome of elderly versus younger patients undergoing major hepatic or pancreatic surgery. Clin Interv Aging 2018;13:133141. 